\title{
Age-Associated Increase in Abdominal Obesity and Insulin Resistance, and Usefulness of AHA/NHLBI Definition of Metabolic Syndrome for Predicting Cardiovascular Disease in Japanese Elderly with Type 2 Diabetes Mellitus
}

\author{
Takashi Sakurai $^{\mathrm{a}}$ Satoshi limuro $^{\mathrm{b}}$ Atsushi Arakic Hiroyuki Umegaki ${ }^{\mathrm{d}}$ \\ Yasuo Ohashi $^{\mathrm{b}}$ Koichi Yokono $^{\mathrm{a}}$ Hideki Ito $^{\mathrm{c}}$ \\ ${ }^{a}$ Department of Internal and Geriatric Medicine, Kobe University Graduate School of Medicine, Kobe, \\ ${ }^{b}$ Department of Biostatistics/Epidemiology and Preventive Health Sciences, School of Health Sciences and Nursing, \\ Tokyo University, Tokyo, ' Department of Endocrinological Medicine, Tokyo Metropolitan Geriatric Medical Center, \\ Tokyo, and d Department of Geriatrics, Nagoya University Graduate School of Medicine, Aichi, Japan
}

\section{Key Words}

Diabetes $\cdot$ Obesity $\cdot$ Waist circumference $\cdot$ Insulin

resistance $\cdot$ Metabolic disease clustering

\begin{abstract}
Background: Management of metabolic syndrome (MetS) seems to constitute an efficient strategy to attain successful ageing. Although the clinical entity of MetS in patients with diabetes mellitus has been discussed, there is very little information on MetS-type cardiometabolic risk factor clustering in diabetic elderly. Objective: To determine the relationship among age-associated changes in obesity, insulin resistance, and clustering of MetS-type risk factors, in association with vascular complications, in Japanese elderly with type 2 diabetes. Methods: A cross-sectional study was conducted of 812 diabetic elderly enrolled in the Japanese Elderly Diabetes Intervention Trial. Information on diabetes, blood examinations and complications was obtained. Abdominal obesity, insulin resistance and prevalence of MetS risk factor clustering, defined by three sets of criteria from the International Diabetes Federation (IDF), the Japanese Society of Internal Medicine (JSIM), and the American Heart
\end{abstract}

\section{KARGER}

Fax +4161306 1234

E-Mail karger@karger.ch

www.karger.com
(C) 2009 S. Karger AG, Basel

0304-324X/10/0562-0141\$26.00/0

Accessible online at:

www.karger.com/ger
Association and the National Heart, Lung, and Blood Institute (AHA/NHLBI), were analyzed. Results: Waist circumference and insulin resistance estimated by homeostasis model assessment insulin resistance (HOMA-IR) increased with age, followed by a partial decrease at age 80 and over. Prevalence of IDF-MetS and JSIM-MetS also increased with age at least until the age of 80 , whereas the incidence of AHA/ $\mathrm{NHLBI}-\mathrm{MetS}$ did not show any apparent age changes. There was a significant crude linear association between waist circumference and HOMA-IR, which was highly elevated in IDF and $\mathrm{AHA} / \mathrm{NHLBl}$ overlapping with MetS, and also elevated in AHA/NHLBI without abdominal obesity. Although IDF-MetS and JSIM-MetS, which specify abdominal obesity, did not always appear to be associated with cardiovascular diseases, AHA/NHLBI-MetS, comprising both abdominal obesity and non-abdominal obesity, independently correlated with coronary heart disease and stroke after adjustment for other risk factors of atherosclerotic diseases. Conclusion: There was an age-associated increase in the prevalence of abdominal obesity and insulin resistance in elderly diabetic Japanese subjects, with a clear relationship between waist circumference and insulin resistance. However, insulin resistance was elevated not only in cases with but also in those 
without abdominal obesity if accompanied by clustering of metabolic disorders. The AHA/NHLBI definition of MetS proved to be the most useful to predict cardiovascular disease in the diabetic elderly.

Copyright $\odot 2009$ S. Karger AG, Basel

\section{Introduction}

Metabolic syndrome (MetS) consists of multiple, interrelated risk factors of metabolic origin that appear to directly promote the development of cardiovascular disease. Recently, MetS has been reported to be associated with impaired activities of daily living (ADLs) and cognitive decline of the elderly $[1,2]$. Thus, management of risk factors and prevention of MetS seem to constitute an efficient strategy to attain successful ageing. Although insulin resistance and visceral adiposity could play a pivotal role in promoting atherosclerosis, the real cause may be a more complex interaction between genetic and environmental factors $[3,4]$.

The clinical usefulness of MetS for risk prediction for individuals with type 2 diabetes remains a matter of debate. It has been reported that insulin resistance and MetS are predictive of accelerated atherosclerosis in type 2 diabetic patients [5-14]. On the other hand, a recent reappraisal of MetS endorsed by the American Diabetes Association and the European Association for the Study of Diabetes argues that MetS is an entity of little or no prognostic use for diabetic patients [15]. They emphasized that it remains unclear whether identification of MetS confers a clinical advantage over identification and treatment of its individual components. Although the term MetS may not be applicable to diabetic subjects, even detractors agree that there are diabetic elderly who have increased insulin resistance associated with MetStype cardiometabolic risk factor clustering [5-14].

Moreover, ageing is associated with increased insulin resistance in addition to type 2 diabetes [16]. Thus, the impact of abdominal obesity on insulin resistance and clustering of metabolic risk factors in diabetic elderly remains unknown. To date, for Asian elderly with type 2 diabetes, there is limited information on age-associated changes in abdominal obesity, insulin resistance and clustering of metabolic risk factors, and their association with vascular complications.

To address the need for elucidation concerning metabolic risk factor clustering in diabetic elderly, we conducted a large-scale prospective study of the Japanese Elderly Diabetes Intervention Trial (J-EDIT) $[17,18]$. The questions we addressed were: (1) prevalence of abdominal obesity, insulin resistance, and MetS-type risk factor clustering as defined by different sets of criteria; (2) possible connections between abdominal obesity and insulin resistance, and (3) the predictive power of MetS-type clustering of metabolic risk factors for cardiovascular diseases in diabetic elderly. To answer these questions, we analyzed the baseline measures of the J-EDIT.

\section{Methods}

\section{Participants}

J-EDIT started in 2001 with an enrolment of 1,173 diabetic subjects aged 65 years or over and with serum HbAlc levels of $\geq 7.0 \%$ from 42 institutes in Japan. The J-EDIT protocol, which is in accordance with the provisions of the Declaration of Helsinki, received ethical approval from the institutional review boards of all of the participating institutes. Written informed consent was obtained from all patients. All examinations relevant for this study were completed by 812 subjects, 371 of whom were men. The remaining 361 subjects were excluded because some of their data were missing.

\section{Diagnostic Criteria for MetS}

In this study, we applied the three different sets of criteria proposed for the diagnosis of MetS by the International Diabetes Federation (IDF), the Japanese Society of Internal Medicine (JSIM) and the American Heart Association and the National Heart, Lung, and Blood Institute (AHA/NHLBI) [19-21]. According to IDF and JSIM criteria, there is a strong correlation between abdominal obesity and insulin resistance, which makes the presence of abdominal obesity a condition for diagnosis of MetS [19,20]. A Japanese study concluded that a visceral fat area in excess of 100 $\mathrm{cm}^{2}$ measured by means of CT scanning corresponds to a waist circumference of $85 \mathrm{~cm}$ for men and $\geq 90 \mathrm{~cm}$ for women [22]. In 2005 , moreover, the IDF recognized specific cutoffs by sex and ethnicity [23]. However, new data support the use of alternative waist circumference cutoffs for the prediction of cardiovascular complications [24-26]. In 2007, the IDF recommended new waist circumference cutoffs for Japanese, $90 \mathrm{~cm}$ for men and $80 \mathrm{~cm}$ for women [19]. However, these cutoffs for waist circumference in the definition of MetS for Japanese have remained a matter of debate. For our study, we therefore adopted two criteria, one from the IDF (2007) and one from the JSIM. On the other hand, AHA/NHLBI has introduced alternative criteria, which have the advantage of avoiding emphasis on a single cause [21]. The resulting three definitions for MetS are as follows.

(1) The IDF definition of MetS (IDF-MetS) specifies abdominal obesity with waist circumference cutoffs of $\geq 90 \mathrm{~cm}$ for men or $\geq 80 \mathrm{~cm}$ for women plus any one of the following factors [19]: (a) elevated triglyceride ( $\geq 150 \mathrm{mg} / \mathrm{dl}$ ) or specific treatment for this lipid abnormality; (b) reduced HDL-cholesterol of $<40$ $\mathrm{mg} / \mathrm{dl}$ for men or $<50 \mathrm{mg} / \mathrm{dl}$ for women, and (c) elevated systolic blood pressure $(\geq 130 \mathrm{~mm} \mathrm{Hg}$ ) or diastolic blood pressure $(\geq 85$ $\mathrm{mm} \mathrm{Hg}$ ) or treatment for previously diagnosed hypertension. 
Table 1. Demographic and clinical parameters of the patients

\begin{tabular}{lccc}
\hline & Male & Female & All subjects \\
\hline $\mathrm{n}$ & 371 & 441 & 812 \\
Age, years & $71.4 \pm 4.5$ & $72.0 \pm 4.6$ & $71.8 \pm 4.6$ \\
Duration of diabetes, years & $16.7 \pm 10.2$ & $15.7 \pm 8.8$ & $16.2 \pm 9.5$ \\
Systolic blood pressure, mm Hg & $137.1 \pm 15.8$ & $138.6 \pm 17.3$ & $137.9 \pm 16.7$ \\
Diastolic blood pressure, mm Hg & $76.2 \pm 9.6$ & $75.5 \pm 10.0$ & $75.8 \pm 9.9$ \\
HbAlc, \% & $8.0 \pm 0.9$ & $8.0 \pm 0.9$ & $8.0 \pm 0.9$ \\
Fasting plasma glucose, mg/dl & $169.7 \pm 50.5$ & $165.1 \pm 50.7$ & $167.2 \pm 50.6$ \\
Fasting plasma insulin, $\mu \mathrm{U} / \mathrm{ml}$ & $9.3 \pm 10.0$ & $10.2 \pm 8.5$ & $9.8 \pm 9.3$ \\
Urine Alb, mg/g Cr & $226.4 \pm 597.9$ & $184.5 \pm 499.7$ & $203.7 \pm 546.8$ \\
Serum cholesterol, mg/dl & $192.7 \pm 31.2$ & $209.5 \pm 34.5$ & $201.8 \pm 34.1$ \\
Serum HDL-C, mg/dl & $52.9 \pm 15.5$ & $60.3 \pm 19.4$ & $56.9 \pm 18.1$ \\
Serum LDL-C, mg/dl & $114.9 \pm 28.0$ & $123.7 \pm 32.0$ & $119.7 \pm 30.5$ \\
Serum triglyceride, mg/dl & $129.2 \pm 84.1$ & $129.4 \pm 66.4$ & $129.3 \pm 74.9$ \\
Current smokers, \% & 28.4 & 5.8 & 16.2 \\
OHA use, \% & 62.5 & 61.7 & 62.1 \\
Insulin use, \% & 25.3 & 31.1 & 28.5 \\
Medication for hypertension, \% & 47.3 & 61.9 & 55.1 \\
Medication with fibrates, \% & 3.2 & 4.3 & 3.8 \\
Medication with statin, \% & 18.9 & 43.1 & 32.0 \\
History of CHD, \% & 15.5 & 15.6 & 15.6 \\
History of stroke, \% & 14.7 & 11.3 & 12.9 \\
\hline
\end{tabular}

Data are presented as means \pm SD or as percentages. $\mathrm{OHA}=$ Oral antihyperglycemic agents; $\mathrm{CHD}=$ coronary heart disease.
(2) The JSIM definition of MetS (JSIM-MetS) specifies abdominal obesity with waist circumference cutoffs of $\geq 85 \mathrm{~cm}$ for men or $\geq 90 \mathrm{~cm}$ for women, plus any one of the following factors [20]: (a) elevated triglyceride $(\geq 150 \mathrm{mg} / \mathrm{dl}$ ) or reduced HDL-cholesterol ( $<40 \mathrm{mg} / \mathrm{dl})$ or specific treatment for these lipid abnormalities, and (b) elevated systolic blood pressure ( $\geq 130 \mathrm{~mm} \mathrm{Hg}$ ) or diastolic blood pressure ( $\geq 85 \mathrm{~mm} \mathrm{Hg}$ ) or treatment for previously diagnosed hypertension.

(3) The AHA/NHLBI definition of MetS (AHA/NHLBI-MetS) specifies two or more of the following conditions [21]: (a) waist circumference of $\geq 90 \mathrm{~cm}$ for men or $\geq 80 \mathrm{~cm}$ for women; (b) elevated triglyceride ( $\geq 150 \mathrm{mg} / \mathrm{dl}$ ) or specific treatment for lipid abnormality; (c) reduced HDL-cholesterol of $<40 \mathrm{mmol} / \mathrm{l}$ for men or $50 \mathrm{mmol} / \mathrm{l}$ for women, and (d) elevated systolic blood pressure $(\geq 130 \mathrm{~mm} \mathrm{Hg}$ ) or diastolic blood pressure $(\geq 85 \mathrm{~mm} \mathrm{Hg}$ ) or treatment for previously diagnosed hypertension.

\section{Assessment of Diabetes Mellitus and Complications}

Information about diabetes mellitus, blood examinations and complications were obtained from clinical charts. Waist circumference was measured at the umbilicus level. Information regarding cigarette smoking was collected using a standardized questionnaire.

After overnight fasting, blood samples were taken by vein puncture to assess serum levels of glucose, HbAlc, total cholesterol, triglyceride, and HDL-cholesterol. Insulin resistance was assessed from levels of fasting glucose and insulin concentration by means of the homeostasis model assessment (HOMA) formula: fasting insulin $(\mu \mathrm{U} / \mathrm{ml}) \times$ fasting glucose $(\mathrm{mg} / \mathrm{dl}) / 405$ [27].
This method was not applicable to subjects treated with insulin. Serum LDL-cholesterol levels were calculated using Friedewald's equation, except for triglyceride levels of $>400 \mathrm{mg} / \mathrm{dl}$, in which case the LDL cholesterol data were recorded as 'missing'.

Information about a previous history of coronary heart disease (CHD) and stroke and findings from a 12-lead electrocardiogram (ECG) were obtained for all patients to assess cardiovascular disease at baseline. CHD was considered to be present when diabetic patients had at least one of the following: a history of myocardial infarction and angina characterized by a typical clinical picture (chest pain, chest oppression, dyspnea, typical ECG alteration). Stroke events were defined as a constellation of neurological deficits of sudden or rapid onset for which there was no apparent cause other than a vascular accident. Cases with asymptomatic lesions detected by brain imaging were not included.

\section{Statistical Analysis}

Data are presented as means \pm SD or as percentages unless otherwise specified. Association of waist circumference with HOMA insulin resistance (HOMA-IR) was tested using simple and multiple logistic regression. Variables among the MetS subgroups were compared using ANOVA and statistical differences were tested with Dunnett's statistical test. Backward logistic regression analysis was used to calculate the adjusted odds ratio (OR) and 95\% confidence interval (CI) for risk factors with cardiovascular diseases. The SAS software package (Version 8.0; SAS, Cary, N.C., USA) was used for all analyses. $\mathrm{p}<0.05$ was considered significant. 
Table 2. Age-associated changes in BMI, waist circumference, HOMA-IR, and prevalence of MetS risk factors

\begin{tabular}{|c|c|c|c|c|c|c|c|c|}
\hline & \multicolumn{4}{|c|}{ Men, age group } & \multicolumn{4}{|c|}{ Women, age group } \\
\hline & $65-69$ & $70-74$ & $75-79$ & $80-85$ & $65-69$ & $70-74$ & $75-79$ & $80-85$ \\
\hline BMI & $23.8 \pm 3.2$ & $23.9 \pm 3.1$ & $23.9 \pm 3.1$ & $23.6 \pm 2.7$ & $23.6 \pm 3.5$ & $24.1 \pm 3.8$ & $24.5 \pm 3.7$ & $22.8 \pm 3.3$ \\
\hline Waist circumference, $\mathrm{cm}$ & $85.8 \pm 8.9$ & $85.0 \pm 8.1$ & $87.6 \pm 8.1$ & $88.3 \pm 10.0$ & $80.6 \pm 10.4$ & $82.7 \pm 10.7$ & $84.5 \pm 11.2$ & $79.6 \pm 10.2$ \\
\hline HOMA-IR & $3.81 \pm 4.0$ & $3.37 \pm 3.1$ & $4.37 \pm 5.8$ & $2.83 \pm 2.0$ & $3.17 \pm 2.7$ & $3.49 \pm 3.0$ & $4.80 \pm 3.6$ & $3.54 \pm 4.1$ \\
\hline IDF-MetS, \% & 28.6 & 30.4 & 33.3 & 42.1 & 47.9 & 59.6 & 59.6 & 46.9 \\
\hline JSIM-MetS, \% & 51.7 & 47.4 & 59.7 & 68.4 & 19.4 & 23.0 & 31.7 & 25.0 \\
\hline AHA/NHLBI-MetS, \% & 56.5 & 52.6 & 59.7 & 57.9 & 72.2 & 83.2 & 80.8 & 65.6 \\
\hline Hypertension, \% & 79.6 & 74.6 & 84.5 & 84.2 & 77.8 & 87.6 & 91.3 & 96.9 \\
\hline \multicolumn{9}{|l|}{ IDF and AHA/NHLBI } \\
\hline Low HDL-C, \% & 38.1 & 30.6 & 35.2 & 31.6 & 60.4 & 65.8 & 65.4 & 46.9 \\
\hline High triglyceride, \% & 26.5 & 30.6 & 25.4 & 36.8 & 29.2 & 36.6 & 30.8 & 25.0 \\
\hline JSIM dyslipidemia, \% & 36.1 & 37.3 & 33.8 & 47.4 & 30.6 & 39.1 & 32.7 & 28.1 \\
\hline
\end{tabular}

Data are presented as means \pm SD or as percentages. BMI = Body mass index; HOMA-IR = homeostasis model assessment, insulin resistance; MetS = metabolic syndrome; IDF = International Diabetes Federation; JSIM = Japanese Society of Internal Medicine; AHA/NHLBI = American Heart Association and the National Heart, Lung, and Blood Institute.

\section{Results}

Age-Associated Increase in Abdominal Obesity, Insulin Resistance and MetS-Type Risk Factor

Clustering

Demographic and clinical parameters of the 812 study participants are listed in table 1. Age-associated changes in BMI, waist circumference, and HOMA-IR are listed in table 2. BMI did not show any apparent changes for men, although waist circumference increased with age. Waist circumference also increased for women, followed by a decrease at the age of 80 or over. HOMA-IR similarly increased with age, but decreased from the age of 80 for both men and women. The increase in insulin resistance seemed to correlate with the age-associated increase in abdominal obesity of diabetic elderly.

The overall prevalence of MetS-type risk factor clustering based on IDF, JSIM and AHA/NHLBI criteria was $44.0,37.1$ and $67.7 \%$, respectively. The incidence of IDFMetS and JSIM-MetS, which specify abdominal obesity, increased with age, but decreased at age 80 or over for women (table 2). In contrast, the prevalence of AHA/NHLBIMetS did not show any apparent change with ageing.

As for the individual components of MetS, the prevalence of hypertension was highest and increased with age. Among diabetic elderly aged $80-85$ years, hypertension was found in $84.2 \%$ of men and $96.9 \%$ of women. The prevalence of low HDL-cholesterol also increased with age, but started to decrease at the age of 80 and over.
We also investigated whether diabetic patients with a longer history of diabetes and/or more serious hyperglycemia might show an increased prevalence of MetS-type risk factor clustering, but no such trend could be found in any type of criteria-defined MetS (data not shown).

\section{Possible Connections between Abdominal Obesity and Insulin Resistance}

Overall, HOMA-IR was $4.2 \pm 5.0$ for diabetic elderly. The relationship between waist circumference and insulin resistance is shown in figure 1 . Simple regression analysis showed that log-transformed HOMA-IR was associated with waist circumference in a crude linear manner (coefficient $=0.051, \mathrm{p}<0.0001, \mathrm{R}^{2}=0.105$ for men; coefficient $=0.034, \mathrm{p}<0.0001, \mathrm{R}^{2}=0.116$ for women). This was demonstrated by an increase in HOMA-IR of 1.1 for men and 0.6 for women for every $10-\mathrm{cm}$ increment in waist circumference. After adjustment for sex, age, systolic blood pressure, HbAlc, triglyceride, and HDL-C, the association remained statistically significant (coefficient $=0.034, \mathrm{p}<0.0001$ ).

For any of the three definitions, HOMA-IR was higher for subjects with MetS than for those without MetS $(4.34 \pm 3.65$ for IDF-MetS and $3.21 \pm 3.50$ for nonIDF-MetS, $\mathrm{p}=0.0003 ; 4.33 \pm 3.95$ for JSIM-MetS and $3.30 \pm 3.33$ for non-JSIM-MetS, $\mathrm{p}=0.0022 ; 4.03 \pm 3.58$ for AHA/NHLBI-MetS and $3.04 \pm 3.57$ for non-AHA/ NHLBI-MetS, $\mathrm{p}=0.0022$ ). 
Fig. 1. Relationship between waist circumference and insulin resistance. Association of HOMA-IR with waist circumference of men (a) and women (b) in the J-EDIT. Logtransformed HOMA-IR (log HOMA-IR) was associated with waist circumference in a crude linear manner (coefficient $=$ $0.051, \mathrm{p}<0.0001, \mathrm{R}^{2}=0.105$ for men; coefficient $=0.034, \mathrm{p}<0.0001, \mathrm{R}^{2}=0.116$ for women).

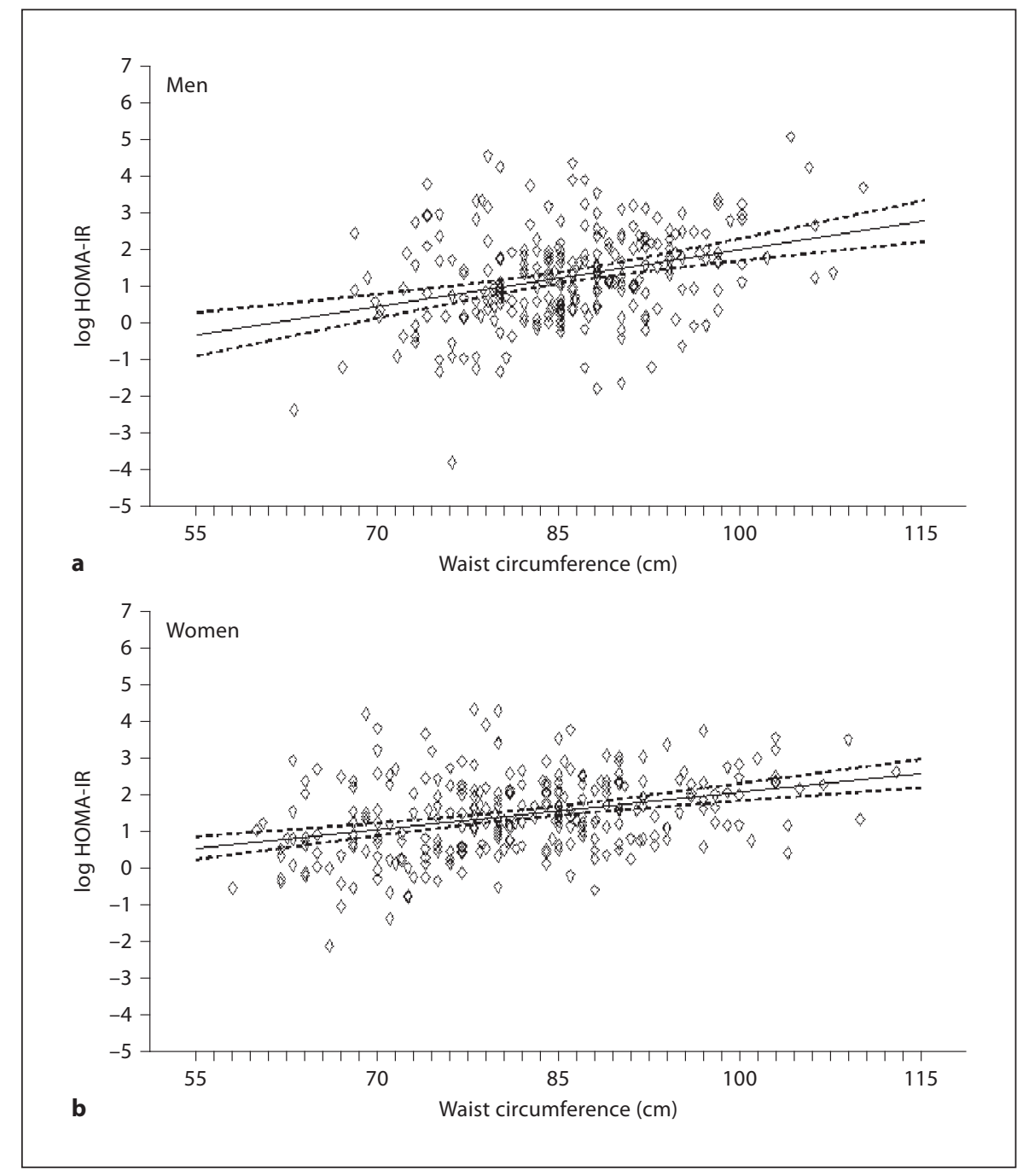

It has been proposed that HOMA-IR is useful for estimating insulin resistance of type 2 diabetic patients [28], but the degree of association between HOMA-IR and clamp insulin resistance for diabetic patients treated with oral antihyperglycemic agents of the class insulin secretagogues has remained unclear. In this connection, Emoto et al. [29] have reported that HOMA-IR strongly correlates with clamp insulin resistance in type 2 diabetic patients treated with sulfonylureas (SUs) as well as in those treated with diet alone. Furthermore, Spearman's correlation coefficients for HOMA-IR and waist circumference were similar for subjects taking SU drugs and those who had used neither SU drugs nor glinides (data not shown). Such evidence indicates that it seems likely that waist circumference is associated with insulin resistance in diabetic elderly, regardless of treatment with oral antihyperglycemic agents of the class insulin secretagogues.

Insulin Resistance of Metabolic Factor Clustering with and without Abdominal Obesity

We compared the clinical characteristics of IDF-MetS and AHA/NHLBI-MetS by dividing the study population into 3 subgroups, non-MetS, AHA/NHLBI-only, and IDF\&AHA/NHLBI (table 3). There was no difference in age among the subgroups. HOMA-IR was especially elevated in the IDF\&AHA/NHLBI group, as was waist circumference. Interestingly, in the AHA/NHLBI-only group, HOMA-IR was moderately elevated without an accompanying increase in waist circumference. Furthermore, the mean duration of diabetes for MetS with overlapping patterns was significantly shorter than that for 
Table 3. Clinical characteristics of subgroups of IDF-MetS and AHA/NHLBI-MetS risk factor clustering

\begin{tabular}{llll}
\hline & Non-MetS & $\begin{array}{l}\text { AHA/ } \\
\text { NHLBI only NHLBI }\end{array}$ & $\begin{array}{l}\text { IDF\&AHA/ } \\
\text { NHLE }\end{array}$ \\
& 263 & 192 & 357 \\
Number & $71.9 \pm 4.7$ & $71.0 \pm 4.5$ & $72.1 \pm 4.5$ \\
Age, years & $78.2 \pm 7.9$ & $77.7 \pm 6.8$ & $91.4 \pm 7.3^{*}$ \\
Waist circumference, cm & $3.04 \pm 3.6$ & $3.46 \pm 3.4$ & $4.34 \pm 3.7^{*}$ \\
HOMA-IR & $16.1 \pm 10.3$ & $14.0 \pm 8.2$ & $13.6 \pm 8.7^{*}$ \\
Duration of diabetes, years & & &
\end{tabular}

For abbreviations see table 2. Data are means \pm SD or actual numbers.

${ }^{*} \mathrm{p}<0.001,{ }^{\dagger} \mathrm{p}=0.004,{ }^{*} \mathrm{p}=0.012$, in comparison with nonMetS.

non-MetS. These results suggest that there are two distinct ways for insulin resistance to increase in diabetic elderly, one is in association with abdominal obesity and the other is not relevant to abdominal obesity.

\section{Association of MetS-Type Risk Factor Clustering with \\ Cardiovascular Disease}

We examined the independent association of MetStype risk factor clustering with cardiovascular diseases (table 4). Because sex is reportedly an independent factor associated with MetS [30-32], MetS and sex were included in the independent variables, while the other risk factors for atherosclerotic disease, such as age, HbAlc, duration of diabetes, smoking, total cholesterol, LDL-cholesterol, triglyceride, systolic blood pressure and diastolic blood pressure, were analyzed with backward stepwise regression. Age was found to be consistently associated with CHD, while JSIM-MetS and AHA/NHLBI-MetS, but not IDF-MetS, were also associated with CHD. When MetS was eliminated from the independent variables, age and diastolic blood pressure proved to be significantly associated with $\mathrm{CHD}$, suggesting these factors independently correlate with CHD in diabetic elderly. For stroke, AHA/ NHLBI-MetS was identified as a predictive factor. When MetS was eliminated from the independent variables, sex (men) and triglyceride showed a significant correlation with stroke. On the other hand, IDF-MetS and JSIM-MetS, which both specify the presence of abdominal obesity for MetS, were not associated with stroke. These results indicate that MetS of AHA/NHLBI definition is the most consistent predictor for CHD and stroke for diabetic elderly, even after adjustment for the risk factors of age, sex, blood pressure, dyslipidemia, and indices of diabetes.
Table 4. Association of MetS and other risk factors with cardiovascular disease

\begin{tabular}{|c|c|c|c|c|c|}
\hline \multicolumn{3}{|c|}{ Previous history of CHD } & \multicolumn{3}{|c|}{ Previous history of stroke } \\
\hline & OR & $95 \% \mathrm{CI}$ & & OR & $95 \% \mathrm{CI}$ \\
\hline \multicolumn{6}{|l|}{$I D F$} \\
\hline MetS & 1.44 & $0.91-2.28$ & MetS & 1.16 & $0.70-1.92$ \\
\hline Sex & 1.39 & $0.88-2.19$ & Sex & 1.69 & $1.03-2.75$ \\
\hline Age & 1.06 & $1.01-1.12$ & Age & 1.05 & $0.99-1.10$ \\
\hline \multirow[t]{2}{*}{ DBP } & 0.98 & $0.95-0.99$ & $\mathrm{TG}$ & 1.01 & $1.00-1.01$ \\
\hline & & & DM duration & 1.25 & $0.89-1.75$ \\
\hline \multicolumn{6}{|l|}{ JSIM } \\
\hline MetS & 1.80 & $1.14-2.85$ & MetS & 1.32 & $0.79-2.19$ \\
\hline Sex & 1.10 & $0.70-1.73$ & Sex & 1.51 & $0.92-2.47$ \\
\hline Age & 1.06 & $1.01-1.11$ & Age & 1.05 & $0.99-1.10$ \\
\hline \multirow[t]{2}{*}{ DBP } & 0.97 & $0.95-0.99$ & $\mathrm{TG}$ & 1.01 & $1.00-1.01$ \\
\hline & & & DM duration & 1.27 & $0.90-1.78$ \\
\hline \multicolumn{6}{|c|}{$A H A / N H L B I$} \\
\hline MetS & 1.90 & $1.13-3.19$ & MetS & 1.86 & $1.07-3.24$ \\
\hline Sex & 1.48 & $0.94-2.33$ & Sex & 1.84 & $1.13-3.00$ \\
\hline Age & 1.06 & $1.01-1.12$ & Age & 1.05 & $0.99-1.11$ \\
\hline DBP & 0.97 & $0.95-0.99$ & & & \\
\hline \multicolumn{6}{|c|}{ Factors other than MetS } \\
\hline Sex & 1.26 & $0.82-1.95$ & Sex & 1.63 & $1.01-2.61$ \\
\hline Age & 1.01 & $1.01-1.12$ & Age & 1.05 & $0.99-1.11$ \\
\hline \multirow[t]{2}{*}{ DBP } & 0.98 & $0.96-0.99$ & $\mathrm{TG}$ & 1.01 & $1.00-1.01$ \\
\hline & & & DM duration & 1.25 & $0.89-1.75$ \\
\hline
\end{tabular}

MetS = Metabolic syndrome; CHD = coronary heart disease; $\mathrm{SBP}=$ systolic blood pressure; $\mathrm{DBP}=$ diastolic blood pressure; $\mathrm{TG}=$ triglyceride; $\mathrm{DM}=$ diabetes mellitus. For other abbreviations, see table 2 .

The association of IDF-MetS, JSIM-MetS and AHA/NHLBIMetS with cardiovascular disease was examined. MetS and sex were included in the independent variables, and age, $\mathrm{HbAlc}$, duration of diabetes, smoking, total cholesterol, LDL-cholesterol, TG, SBP and DBP were analyzed with backward stepwise regression.

\section{Discussion}

This J-EDIT study first provided evidence of MetStype risk factor clustering in Asian (Japanese) elderly with type 2 diabetes. Several new findings are reported: (1) abdominal obesity, insulin resistance and prevalence of MetS-type risk factor clustering evidently increased with age, but somewhat decreased at the age of 80 and over; (2) overall insulin resistance was substantially elevated in diabetic elderly $[28,30]$, and there was a significant crude linear association between waist circumference and insulin resistance; (3) insulin resistance was elevated not only in cases with but also without abdominal 
obesity if accompanied by clustering of metabolic disorders, and (4) AHA/NHLBI-MetS, comprising both abdominal obese and non-abdominal obese metabolic factor clustering cases, was the most useful for prediction of cardiovascular disease in diabetic elderly.

The incidence of MetS in the general population reportedly differs widely among ethnic groups and according to the definition of MetS [13, 33-38]. It has also been reported that the prevalence of MetS increases with age $[39,40]$. However, the prevalence of MetS-type risk factor clustering among patients with known diabetes is consistently high regardless of ethnicity or definition $[6-13,30$, 33, 41-48]. In the Japan Diabetes Complications Studies (JDCS), which was concerned with relatively younger diabetic patients aged 40-70 years, the prevalence of IDFMetS risk factor clustering was 32\% for men and $9.2 \%$ for women [47]. Although the inclusion criteria of JDCS and JEDIT were not the same, it seems likely that prevalence of MetS-type risk factor clustering in Japanese patients with type 2 diabetes increases with age, at least until the age of 80 . To our knowledge, there are no epidemiological data of MetS-type risk factor clustering of diabetic elderly in the other ethnic groups.

Although we did not measure insulin resistance directly in this study, HOMA-IR has been shown to correlate well with direct methods in subjects with various degrees of glucose tolerance, including patients who have already developed diabetes [27]. The averages of HOMA-IR of younger diabetic subjects have been reported as 2.9-3.3 $[28,30]$. In our diabetic elderly, insulin resistance was evidently high $(4.2 \pm 5.0)$, which may be due to the diabetic state itself and/or age-associated changes in body composition such as increases in fat mass and decreases in fat-free mass [16]. We therefore expected that the correlation of insulin resistance with abdominal obesity might become weaker in diabetic elderly, but there was in fact a significant linear association of insulin resistance with waist circumference, and the former was found to be higher in JSIM-MetS and IDF-MetS. In this respect, it should be pointed out that insulin resistance also increased moderately in MetS-type risk factor clustering without abdominal obesity, so that the mechanism for the increase in insulin resistance associated with non-obese type metabolic factor clustering remains to be clarified [40].

Evidence is accumulating that MetS is clinically relevant for the prediction of cardiovascular disease in nondiabetic elderly [49-51]. Our study is the first to demonstrate that AHA/NHLBI-MetS correlates independently with cardiovascular disease in diabetic elderly after adjustment for the other risk factors for atherosclerotic dis- ease. It seems plausible that non-obese metabolic factor clustering together with increased insulin resistance has a major impact on the risk of cardiovascular diseases of diabetic elderly, because MetS with abdominal obesity does not always appear to be associated with cardiovascular diseases [10, 52-54]. Definitions of MetS-type risk factor clustering that specify abdominal obesity have not yet been developed for Asian (Japanese) diabetic elderly. Other studies have also identified the usefulness of the National Cholesterol Education Program (NCEP)-MetS and AHA/NHLBI-MetS for the prediction of cardiovascular disease in younger subjects with type 2 diabetes [9$10,13]$. On the other hand, Sone et al. [30] have demonstrated that NCEP-MetS has limited clinical usefulness as a predictor for Asian diabetic patients. Further prospective analyses are thus needed to investigate the clinical significance of MetS-type risk factor clustering without abdominal obesity for diabetic elderly.

There are certain limitations to our study. First, we performed a cross-sectional evaluation and our results are therefore subject to survival bias. Second, our study subjects were hospital-based patients with diabetes of relatively long duration, so that any inferences are of necessity limited to similar patient groups. On the other hand, this population sample represents the real-world scenario of type 2 diabetes in Japan.

In conclusion, abdominal obesity and insulin resistance were found to increase with age, at least until the age of 80, in Asian diabetic elderly, and a relationship between waist circumference and HOMA-IR was demonstrated. An important finding was that MetS-type metabolic factor clustering without abdominal obesity also showed elevated insulin resistance. AHA/NHLBI-MetS, comprising both obese and non-obese metabolic disease clustering, was found to be the most effective for the prediction of cardiovascular disease, whilst the significance of MetS with abdominal obesity in this respect remains unclear. An on-going prospective study of J-EDIT may help to clarify the pathophysiology of metabolic disease clustering and its association with cardiovascular disease and geriatric syndromes of diabetic elderly.

\section{Acknowledgements}

This study was financially supported by the Ministry of Health, Labor, and Welfare of Japan. We wish to thank all patients, physicians, and staff who took part in the J-EDIT. All authors received Health and Labor Science Research Grants for Comprehensive Research on Aging and Health (H12-016, H15-16, H17-013) from the Ministry of Health, Labor and Welfare, Japan. 


\section{References}

-1 Yaffe K, Kanaya A, Lindquist K, Simonsick E, Harris T, Shorr R, Tylavsky F, Newman A: The metabolic syndrome, inflammation, and risk of cognitive decline. JAMA 2004; 292:2237-2242.

-2 Roriz-Cruz M, Rosset I, Wada T, Sakagami T, Ishine M, Roriz-Filho J, Cruz T, Rodrigues R, Resmini I, Sudoh S, Wakatsuki Y, Nakagawa M, Souza A, Kita T, Matsubayashi K: Stroke-independent association between metabolic syndrome and functional dependence, depression, and low quality of life in elderly community-dwelling Brazilian people. J Am Geriatr Soc 2007;55:374-382.

$\checkmark 3$ Grundy S: What is the contribution of obesity to the metabolic syndrome? Endcrinol Metab Clin North Am 2004;33:267-282.

4 Eckel R, Grundy S, Zimmet P: The metabolic syndrome. Lancet 2005;365:1415-1428.

$>5$ Bonora E, Formentini G, Calcaterra F, Lombardi S, Marini F, Zenari L, Saggiani F, Poli M, Perbellini S, Raffaelli A, Cacciatori V, Santi L, Targher G, Bonadonna R, Muggeo M: HOMA-estimated insulin resistance is an independent predictor of cardiovascular disease in type 2 diabetic subjects: prospective data from the Verona Diabetes Complications Study. Diabetes Care 2002;25:1135-1141.

$\checkmark 6$ Alexander C, Landsman P, Teutsch S, Haffner S; Third National Health and Nutrition Examination Survey (NHANES III); National Cholesterol Education Program (NCEP): NCEP-defined metabolic syndrome, diabetes, and prevalence of coronary heart disease among NHANES III participants age 50 years and older. Diabetes 2003; 52:1210-1214.

$>7$ Bonora E, Targher G, Formentini G, Calca- $>16$ terra F, Lombardi S, Marini F, Zenari L, Saggiani F, Poli M, Perbellini S, Raffaelli A, Gemma L, Santi L, Bonadonna RC, Muggeo $\mathrm{M}$ : The metabolic syndrome is an independent predictor of cardiovascular disease in type 2 diabetic subjects. Prospective data from the Verona Diabetes Complications Study. Diabet Med 2004;21:52-58.

$>8$ Isomaa B, Almgren P, Tuomi T, Forsen B, Lahti K, Nissen M, Taskinen M, Groop L: Cardiovascular morbidity and mortality associated with the metabolic syndrome. Diabetes Care 2001;24:683-689.

$>9$ Monami M, Marchionni N, Masotti G, Mannucci E: IDF and ATP-III definitions of metabolic syndrome in the prediction of allcause mortality in type 2 diabetic patients. Diabetes Obes Metab 2007;9:350-353.

- 10 Tong P, Kong A, So WY, Yang X, Ho C, Ma R, Ozaki R, Chow C, Lam C, Chan J, Cockram C: The usefulness of the International Diabetes Federation and the National Cholesterol Education Program's Adult Treatment Panel III definitions of the metabolic syndrome in predicting coronary heart disease in subjects with type 2 diabetes. Diabetes Care 2007;30:1206-1211.
11 Metascreen Writing Committee, Bonadonna R, Cucinotta D, Fedele D, Riccardi G, Tiengo A: The metabolic syndrome is a risk indicator of microvascular and macrovascular complications in diabetes: results from Metascreen, a multicenter diabetes clinicbased survey. Diabetes Care 2006;29:27012707.

12 Ko G, So W, Chan N, Chan W, Tong P, Li J, Yeung V, Chow C, Ozaki R, Ma R, Cockram C, Chan J: Prediction of cardiovascular and total mortality in Chinese type 2 diabetic patients by the WHO definition for the metabolic syndrome. Diabetes Obes Metab 2006; 8:94-104.

13 de Simone G, Devereux R, Chinali M, Best L, Lee E, Galloway J, Resnick H; Strong Heart Study Investigators: Prognostic impact of metabolic syndrome by different definitions in a population with high prevalence of obe sity and diabetes: the Strong Heart Study. Diabetes Care 2007;30:1851-1856.

14 Hanefeld M, Koehler C, Gallo S, Benke I, Ott P: Impact of the individual components of the metabolic syndrome and their different combinations on the prevalence of atherosclerotic vascular disease in type 2 diabetes: the Diabetes in Germany (DIG) study. Cardiovasc Diabetol 2007;6:13

15 Kahn R, Buse J, Ferrannini E, Stern M; American Diabetes Association; European Association for the Study of Diabetes: The metabolic syndrome: time for a critical appraisal: joint statement from the American Diabetes Association and the European Association for the Study of Diabetes. Diabetes Care 2005;28:2289-2304.

16 Karakelides H, Sreekumaran Nair K: Sarcopenia of aging and its metabolic impact. Curr Top Dev Biol 2005;68:123-148.

17 Akisaki T, Sakurai T, Takata T, Umegaki H, Araki A, Mizuno S, Tanaka S, Ohashi Y, Iguchi A, Yokono K, Ito $\mathrm{H}$ : Cognitive dysfunction associates with white matter hyperintensities and subcortical atrophy on magnetic resonance imaging of the elderly diabetes mellitus Japanese elderly diabetes intervention trial (J-EDIT). Diabetes Metab Res Rev 2006;22:376-384.

18 Umegaki H, Iimuro S, Kaneko T, Araki A, Sakurai T, Ohashi Y, Iguchi A, Ito H: Factors associated with lower Mini Mental State Examination scores in elderly Japanese diabetes mellitus patients. Neurobiol Aging 2008; 29:1022-1026.

19 International Diabetes Federation: The IDF consensus worldwide definition of metabolic syndrome [article online], 2005 and 2007 (http://www.idf.org/webdata/docs/IDF_ Meta_def_final.pdf).
20 Arai H, Yamamoto A, Matsuzawa Y, Saito Y, Yamada N, Oikawa S, Mabuchi H, Teramoto T, Sasaki J, Nakaya N, Itakura H, Ishikawa Y, Ouchi Y, Horibe H, Shirahashi N, Kita T: Prevalence of metabolic syndrome in the general Japanese population in 2000. J Atheroscler Thromb 2006;13:202-208.

21 Grundy S, Cleeman J, Daniels S, Donato K, Eckel R, Franklin B, Gordon D, Krauss R, Savage P, Smith S Jr, Spertus J, Costa F; American Heart Association; National Heart, Lung, and Blood Institute: Diagnosis and management of the metabolic syndrome: an American Heart Association/National Heart, Lung, and Blood Institute Scientific Statement. Circulation 2005;112:2735-2752.

22 Matsuzawa Y: Metabolic syndrome - definition and diagnostic criteria in Japan. J Atheroscler Thromb 2005;12:301.

23 Alberti KG, Zimmet P, Shaw J; IDF Epidemiology Task Force Consensus Group: The metabolic syndrome - a new worldwide definition. Lancet 2005;366:1059-1062.

24 Hara K, Matsushita Y, Horikoshi M, Yoshiike N, Yokoyama T, Tanaka H, Kadowaki $\mathrm{T}$ : A proposal for the cutoff point of waist circumference for the diagnosis of metabolic syndrome in the Japanese population. Diabetes Care 2006;29:1123-1124.

25 Eguchi M, Tsuchihashi K, Saitoh S, Odawara Y, Hirano T, Nakata T, Miura T, Ura N, Hareyama M, Shimamoto K: Visceral obesity in Japanese patients with metabolic syndrome: reappraisal of diagnostic criteria by CT scan. Hypertens Res 2007;30:315-323.

26 Oka R, Kobayashi J, Yagi K, Tanii H, Miyamoto S, Asano A, Hagishita T, Mori M, Moriuchi T, Kobayashi M, Katsuda S, Kawashiri MA, Nohara A, Takeda Y, Mabuchi H, Yamagishi M: Reassessment of the cutoff values of waist circumference and visceral fat area for identifying Japanese subjects at risk for the metabolic syndrome. Diabetes Res Clin Pract 2008;79:474-481.

27 Wallace T, Levy J, Matthews D: Use and abuse of HOMA modeling. Diabetes Care 2004;27:1487-1495.

28 Matthews D, Hosker J, Rudenski A, Naylor B, Treacher D, Turner R: Homeostasis model assessment: insulin resistance and beta-cell function from fasting plasma glucose and insulin concentrations in man. Diabetologia 1985;28:412-419.

-29 Emoto M, Nishizawa Y, Maekawa K, Hiura Y, Kanda H, Kawagishi T, Shoji T, Okuno Y, Morii H: Homeostasis model assessment as a clinical index of insulin resistance in type 2 diabetic patients treated with sulfonylureas. Diabetes Care 1999;22:818-822. 
-30 Sone H, Mizuno S, Fujii H, Yoshimura Y, Yamasaki Y, Ishibashi S, Katayama S, Saito Y, Ito H, Ohashi Y, Akanuma Y, Yamada N; Japan Diabetes Complications Study: Is the diagnosis of metabolic syndrome useful for predicting cardiovascular disease in Asian diabetic patients? Analysis from the Japan Diabetes Complications Study. Diabetes Care 2005;28:1463-1471.

- 31 De Cosmo S, Minenna A, Ludovico O, Mastroianno S, Di Giorgio A, Pirro L, Trischitta $\mathrm{V}$ : Increased urinary albumin excretion, insulin resistance, and related cardiovascular risk factors in patients with type 2 diabetes: evidence of a sex-specific association. Diabetes Care 2005;28:910-915.

- 32 Mak K, Ma S, Heng D, Tan C, Tai E, Topol E, Chew S: Impact of sex, metabolic syndrome, and diabetes mellitus on cardiovascular events. Am J Cardiol 2007;100:227-233.

- 33 Balkau B, Charles M, Drivsholm T, BorchJohnsen K, Wareham N, Yudkin J, Morris R, Zavaroni I, van Dam R, Feskins E, Gabriel R, Diet M, Nilsson P, Hedblad B, European Group for the Study of Insulin Resistance: Frequency of the WHO metabolic syndrome in European cohorts, and an alternative definition of an insulin resistance syndrome. Diabetes Metab 2002;28:364-376.

34 Park Y, Zhu S, Palaniappan L, Heshka S, Carnethon M, Heymsfield S: The metabolic syndrome: prevalence and associated risk factor findings in the US population from the Third National Health and Nutrition Examination Survey, 1988-1994. Arch Intern Med 2003; 163:427-436

- 35 Meigs J, Wilson P, Nathan D, D’Agostino R Sr, Williams K, Haffner S: Prevalence and characteristics of the metabolic syndrome in the San Antonio Heart and Framingham Offspring Studies. Diabetes 2003;52:21602167.

-36 Thanopoulou A, Karamanos B, Angelico F, Assaad-Khalil S, Djordjevic P, Katsilambros N, Migdalis I, Mrabet M, Petkova M, Roussi D, Tenconi MT, Archimandritis A: Epidemiological evidence for the non-random clustering of the components of the metabolic syndrome: multicentre study of the Mediterranean Group for the Study of Diabetes. Eur J Clin Nutr 2006;60:1376-1383.

37 DECODA Study Group: Prevalence of the metabolic syndrome in populations of Asian origin. Comparison of the IDF definition with the NCEP definition. Diabetes Res Clin Pract 2007;76:57-67.
38 Athyros V, Ganotakis E, Elisaf M, Liberopoulos E, Goudevenos I, Karagiannis A; GREECE-METS Collaborative Group: Prevalence of vascular disease in metabolic syndrome using three proposed definitions. Int J Cardiol 2007;117:204-210.

39 Lawlor D, Ebrahim S, Smith G: The metabolic syndrome and coronary heart disease in older women: findings from the British Women's Heart and Health Study. Diabetic Med 2004;8:906-913.

40 Morino K, Petersen K, Shulman G: Molecular mechanisms of insulin resistance in humans and their potential links with mitochondrial dysfunction. Diabetes 2006; 55(suppl 2):S9-S15.

41 Ilanne-Parikka P, Eriksson JG, Lindstrom J, Hamalainen $\mathrm{H}$, Keinanen-Kiukaanniemi S, Laakso M, Louheranta A, Mannelin M, Rastas M, Salminen V, Aunola S, Sundvall J, Valle T, Lahtela J, Uusitupa M, Tuomilehto J, Finnish Diabetes Prevention Study Group: Prevalence of the metabolic syndrome and its components: findings from a Finnish general population sample and the Diabetes Prevention Study cohort. Diabetes Care 2004; 27:2135-2140.

42 Relimpio F, Martinez-Brocca M, Leal-Cerro A, Losada F, Mangas M, Pumar A, Astorga R: Variability in the presence of the metabolic syndrome in type 2 diabetic patients attending a diabetes clinic: influences of age and gender. Diabetes Res Clin Pract 2004;65: 135-142.

43 Bruno G, Merletti F, Biggeri A, Bargero G, Ferrero S, Runzo C, Prina Cerai S, Pagano G, Cavallo-Perin P; Casale Monferrato Study: Metabolic syndrome as a predictor of allcause and cardiovascular mortality in type 2 diabetes: the Casale Monferrato Study. Diabetes Care 2004;27:2689-2694.

44 Gimeno Orna J, Lou Arnal L, Molinero Herguedas E, Boned Julián B, Portilla Córdoba D: Metabolic syndrome as a cardiovascular risk factor in patients with type 2 diabetes (in Spanish). Rev Esp Cardiol 2004;57:507-513.

45 Costa L, Canani L, Lisboa H, Tres G, Gross J: Aggregation of features of the metabolic syndrome is associated with increased prevalence of chronic complications in type 2 diabetes. Diabet Med 2004;21:252-255.

46 Lee Y, Tsai J: ACE gene insertion/deletion polymorphism associated with 1998 World Health Organization definition of metabolic syndrome in Chinese type 2 diabetic patients. Diabetes Care 2002;25:1002-1008.
47 Sone H, Tanaka S, Ishibashi S, Yamasaki Y, Oikawa S, Ito H, Saito Y, Ohashi Y, Akanuma Y, Yamada N; Japan Diabetes Complications Study (JDCS) Group: The new worldwide definition of metabolic syndrome is not a better diagnostic predictor of cardiovascular disease in Japanese diabetic patients than the existing definitions: additional analysis from the Japan Diabetes Complications Study. Diabetes Care 2006;29:145-147.

48 Koehler C, Ott P, Benke I, Hanefeld M; DIG Study Group: Comparison of the prevalence of the metabolic syndrome by WHO, AHA/ NHLBI, and IDF definitions in a German population with type 2 diabetes: the Diabetes in Germany (DIG) Study. Horm Metab Res 2007;39:632-635.

49 Scuteri A, Najjar S, Morrell C, Lakatta E; Cardiovascular Health Study: The metabolic syndrome in older individuals: prevalence and prediction of cardiovascular events: the Cardiovascular Health Study. Diabetes Care 2005;28:882-887.

50 Butler J, Rodondi N, Zhu Y, Figaro K, Fazio S, Vaughan D, Satterfield S, Newman A, Goodpaster B, Bauer D, Holvoet P, Harris T, de Rekeneire N, Rubin S, Ding J, Kritchevsky S; Health ABC Study: Metabolic syndrome and the risk of cardiovascular disease in older adults. J Am Coll Cardiol 2006;47:15951602.

51 He Y, Jiang B, Wang J, Feng K, Chang Q, Fan L, Li X, Hu F: Prevalence of the metabolic syndrome and its relation to cardiovascular disease in an elderly Chinese population. J Am Coll Cardiol 2006;47:1588-1594.

52 Katzmarzyk PT, Janssen I, Ross R, Church T, Blair S: The importance of waist circumference in the definition of metabolic syndrome: prospective analyses of mortality in men. Diabetes Care 2006;29:404-409.

53 Yoon Y, Lee E, Park C, Lee S, Oh S: The new definition of metabolic syndrome by the international diabetes federation is less likely to identify metabolically abnormal but nonobese individuals than the definition by the revised national cholesterol education program: the Korea NHANES study. Int J Obes (Lond) 2007;31:528-534.

54 Kadota A, Hozawa A, Okamura T, Kadowak T, Nakmaura K, Murakami Y, Hayakawa T, Kita Y, Okayama A, Nakamura Y, Kashiwagi A, Ueshima H; NIPPON DATA Research Group: Relationship between metabolic risk factor clustering and cardiovascular mortality stratified by high blood glucose and obesity: NIPPON DATA90, 1990-2000. Diabetes Care 2007;30:1533-1538.
Obesity, Insulin Resistance, and Metabolic Factor Clustering in Diabetics 